\title{
EKOSISTEM DAKWAH DALAM ERA TEKNOLOGI DISRUPTIF
}

\section{Oleh}

\author{
Zulkefli bin Aini, Phd \\ Pensyarah Program Dakwah dan Kepimpinan \\ Pusat Kesejahteraan Insan dan Komuniti \\ Fakulti Pengajian Islam \\ Universiti Kebangsaan Malaysia \\ zulaini@ukm.edu.my
}

\begin{abstract}
Abstark
Ziauddin Sardar (1993) pernah mengemukakan pendapat tentang beberapa perubahan besar akan berlaku dalam kehidupan umat Islam akibat kemunculan dan penggunaan suatu inovasi dalam teknologi maklumat dan komunikasi (ICT). Ini kerana sepanjang berlakunya perkembangan teknologi yang bermula dengan teknologi kertas, yang diikuti selepas itu teknologi percetakan dan cakera padat, dalam pemerhatian beliau mendapati bahawa peranan ulama sebagai orang yang dianggap menguasai ilmu dan menjadi panduan serta rujukan dalam pembangunan masyarakat Islam akan mengalami pengurangan sedikit demi sedikit. Beliau berhujah:

"The role of the ulama as human memory banks, and the power they command by virtues of that role, is about to end"

Berdasarkan pandangan tersebut, beliau menyimpulkan bahawa keupayaan teknologi baru ICT yang mmempunyai keupayaan mengatasi kemampuan manusia biasa dalam menyimpan, memproses dan mendapatkan maklumat dalam jumlah yang banyak dan boleh dilakukan dengan sangat pantas.Begitu juga dalam pencarian dan pencapaian maklumat tentang Islam yang boleh diakses melalui perisian ICT yang serba canggih, pada pandangan beliau, secara tidak langsung boleh mengurangkan pengaruh penguasaan ilmu oleh para ulama pada masa sekarang.

Persoalannya apakah Islam dan umat Islam serta para ulama perlu meninggalkan atau mengabaikan atau tidak mengendahkan suatu penciptaan baharu dalam dunia yang begitu pantas dengan perkembangan teknologi dengan mempertahankan cara dan pendekatan lama dan konvensional dalam menyebarkan mesej Islam dalam kerangka dakwah kepada umat manusia sedangkan umat mahukan perubahan dan terdedah dengan perubahan? apakah dakwah begitu kaku dan tidak berkembang selari dengan berkembangnya kemajuan sains dan teknologi yang menghasilkan pelbagai invention yang memudahkan urusan umat manusia? apakahmawdu dakwah yang perlu dikongsikan kepada sasaran dakwah yang mempunyai pelbagai latarbelakang yang kedudukannya barangkali sama taraf atau tidak dengan pendakwah? Apakah pendakwah hanya berdiam diri apabila berhadapan dengan mad' $u$ yang pelbagai latarbelakang atau menggunakan pendekatan konvensional atau tradisional menyampaikan mesej Islam dalam kerangka dan iklim dakwah masa kini?
\end{abstract}

Kata Kunci: Ekosistem Dakwah, Teknologi Disruptif 


\section{A. Dakwah antara sesuatu yang pasti (al-thabat) dan anjal (murunah)}

Istilah dakwah bukan istilah ciptaan manusia yang lahir daripada akal fikiran manusia.ia bukan gagasan manusia yang duduk bersidang sambil mencari kesimpulan dan resolusi bagi dipersembahkan kepada khalayak. Ia sudah pasti datang daripada Pencipta yang Maha Berkuasa, Allah Rabb al-'Alamin yang menciptakan manusia sebagai khalifah di atas muka bumi bagi memakmurkan bumi dengan peraturan dan undang-undang Allah SWT (Surah al-Baqarah 30). kepatuhan dan ketundukan manusia kepada Allah SWT adalah kepatuhan yang tidak berbelah bahagi, tanpa soal-tanya, yang ada hanyalah menjalankan perintah Allah SWT sesuai dengan matlamat penciptaannya. Rasul dan Nabi diutuskan sebagai pembimbing dan juru pandu kepada manusia sejagat bagaimanakah caranya mengabdikan diri kepada Allah SWT dengan berpandukan wahyu. Kaedah membimbing, mengajak dan menyeru pun telah dititipkan di dalam kalam suci sebagaimana yang termaktub di dalam surah al-Nahl ayat 125 yang bermaksud: "Serulah ke jalan Tuhanmu (wahai Muhammad) dengan hikmah kebijaksanaan dan nasihat pengajaran yang baik, dan berdebatlah dengan mereka (yang engkau serukan itu) dengan cara yang lebih baik"

Berdasarkan ayat tersebut, al-Bayanuni (1995) menyimpulkan bahawa terdapat ummahat al-asalib yang diperintahkan oleh Allah SWT untuk menjayakan aktiviti pendakwahan, iaitu al-hikmah, al-maw ¿iah al-hasanah dan al-mujadalah al-husna. Ketiga-tiga aspek tersebut juga berkait dengan cara, kaedah atau pendekatan dalam menyampaikan mawdu’ dakwah .Menurut Zulkiple (2010) ketiga-tiga aspek tersebut boleh dianggap sebagai kerangka utama metodologi dakwah yang sesuai untuk dipraktiskan dan diaplikasikan pada sepanjang masa dan pelbagai tempat.Ketiga-tiga metodologi tersebut menempati kedudukan sebagai manhaj rabbani yang merujuk kepada metodologi yang bersumberkan wahyu yang sangat pasti (althabat) dan mutlak kebenarannya (al-Haqq).

Walaupun, metodologi dakwah yang dinyatakan adalah dikategorikan sebagai manhaj rabbani, ia tidaklah menghalang dakwah sebagai suatu usaha yang bersifat dinamik dan berkembang sesuai dengan tabii kejadian manusia. Proses pendakwahan tidak akan berlangsung dengan jayanya jika elemen-elemen seperti pendakwah, kandungan atau mesej dakwah, saluran dan pendekatan, sasaran, kesan dan gangguan tidak diberi perhatian. Malah ada elemen yang bersifat sekundar seperti maklum awal dan maklum balas serta rangka rujuk perlu juga diberikan perhatian supaya proses pendakwahan dapat berlangsung dengan baik (Zulkefli dan S.Salahudin 2016). Justeru, pendakwah yang menggunakan pendekatan dakwah secara al-hikmah, al-maw`izah al-hasanah dan al-mujadalah al-husna yang digarap 
dengan penggunaan wasilah dakwah yang bersesuaian dengan konteks dakwah masa kini akan menjadikan dakwah terus relevan.

\section{B. Pendakwah dan Wasilah Dakwah}

Al-Bayanuni (1995) menyatakan mesej dakwah boleh disampaikan melalui medium atau wasilah hissi.Ia melibatkan peralatan, sistem dan organisasi. Dalam dunia realiti baru, pendakwah perlu mempunyai ilmu pengetahuan dan kompetansi tertentu bagi menguasai dan menggunakan wasilah hissi yang disesuaikan dengan perkembangan teknologi dan komunikasi.Peter Drucker (1995) pernah mengungkapkan istilah realiti baru ini bagi menjelaskan beberapa karekter baharu yang muncul dalam masyarakat yang merubah sebahagian struktur kehidupan manusia tanpa mengambil kira aspek latarbelakang kaum dan anutan kepercayaan beragama.Beliau percaya orang yang menguasai ICT dianggap golongan elit yang mempunyai kelebihan tertentu seperti cara bekerja dan kewujudan masyarakat yang disandarkan dengan K, iaitu Knowledge atau ilmu seperti K-ekonomi, kpekerja dan sebagainya. Namun perkembangan sedemikian membuatkan Hamid Mowlana (1993) merasa bimbang dan sangsi terhadap pembentukan atau kewujudan 'masyarakat bermaklumat'. Beliau berhujah bahawa pembentukan 'masyarakat bermaklumat' sebagaimana yang didakwa terhasil daripada perkembangan teknologi maklumat selari dengan kemunculan masyarakat super-secular yang mempunyai ciri-ciri tertentu seperti semangat penguasaan globalisasi, kepuasan apabila matlamat tercapai, masa (kepantasan) amat bernilai, kemunculan ekonomi sinergetik, maklumat menjadi bahan komoditi utama yang ketandusan nilai moral dan etika serta menjauhkan manusia daripada Tuhan. Oleh itu, menurut Zulkiple (2010) pendakwah yang celik teknologi, berilmu pengetahun dan berhikmah (k-da i) perlu berada dalam lingkungan semangat iqra’ dan ia menjadi kerangka asas dalam operasi dakwah sebagaimana yang ditunjukkan oleh Rasulullah s.a.w.

Bani Amir (1999) membahagikan pendakwah kepada dua kategori, iaitu pendakwah dalam kelompok ‘mmah dan pendakwah dalam kelompok khassah. Kerangka rujuk yang sama antara kedua kelompok tersebut ialah motivasi melakukan pendakwahan kepada masyarakat. Cuma yang membezakan antara keduanya ialah penguasaan mendalam terhadap ilmu-ilmu berteraskan Islam atau apa yang pernah diistilahkan oleh al-Qaradawi dalam kitabnya Thaqafah al-Da iyyah sebagai al-thaqafah al-Islamiyyah. justeru, tidak hairanlah dalam kelompok ‘mmah terdapat golongan professional yang mempunyai pekerjaan sebagai peguam, jurutera, saintis, jurnalis, ahli politik dan sebagainya terlibat 
dalam kerja-kerja dakwah. Mereka mempunyai pengetahuan dalam bidang masing-masing dan mereka cemerlang dalam pekerjaan mereka tetapi masih mahu menempatkan diri dalam dunia dakwah.Keadaan tersebut menjadikan kelompok khassah yang biasa disebut dan dikenali sebagai ustaz dan ustazah mula bergabung tenaga dengan kelompok ‘mmah tersebut bagi menjayakan matlamat dakwah.Malah, mereka bersinargi dalam mempelajari sesuatu pengetahuan yang mereka rasakan ada kekurangan bagi menampung kelemahan dalam gerakgeri dakwah.Ada yang mengikuti pengajian secara formal dengan mendalami bidang-bidang yang tidak pernah dipelajari seperti ilmu kemanusiaan atau human sciences bagi memperlengkapkan keperluan dunia dakwah.Pengajian yang berasaskan major-minor di institusi pendidikan tinggi yang menawarkan kursus yang merentas disiplin ilmu dipelajari bagi mengisi kekosongan dan keperluan masyarakat.Akhirnya, mereka bukan sahaja mampu mengungkapkan istilah dan komentar dalam kitab-kitab fiqh klasik dan semasa, tetapi mampu mengemukakan solusi berasaskan kehendak semasa yang diambil daripada pendekatan konvensional dan kontemporari.Begitu juga kelompok ‘mmah yang terdidik dengan pengetahuan yang berasakan sains dan teknologi misalnya, mula mempelajari falsafah sains yang berteraskan worldview dan epistemology yang bersumberkan wahyu sehingga mereka boleh mengungkapkan istilah islamisasi ilmu pengetahuan dalam kerangkan pembelajaran dan penelitian semasa mereka.Dengan ini, pendakwah yang mempunyai multiskills, multi-knowledge dalam masyarakat berjaya menarik minat golongan sasaran mendekatkan diri dengan Islam dan menjadikan Islam sebagai penyelesaian kepada permasalahan yang timbul dalam kehidupan.

Dalam konteks dakwah dalam era teknologi desruptif, pendakwah boleh berada dalam ruang siber.Persoalannya ialah adakah pendakwah bersedia berada di dalam ruang tersebut sambil memahami perubahan-perubahan yang berlaku di sekelilingnya, terutama dalam konteks komunikasi dakwah yang bersifat global yang menjangkau pelbagai khalayak dan berbeza demografinya. Dengan sifat segala-galanya adalah internet dalam dunia teknologi desruptif, pendakwah harus mengakui kewujudan internet dan kemudahan rangkaian serta persembahan dalam pelbagai bentuk multimedia, misalnya, serta laman-laman web dan aplikasi yang menjadi medan komunikasi yang sangat luas tidak bertepi. Walau bagaimanapun, Zulkiple (2002) mempunyai kerisauan yang sangat berasas apabila beliau mendapati ada yang bersifat lepas-bebas, terkeluar dari tatakawalan budaya, nilai pegangan sesuatu masyarakat, pemerintah malah autoriti Tuhan.Malah dalam kajian terbarunya, Zulkiple (2019) mendapati teknologi yang digunakan oleh negara umat Islam yang diimport 
daripada negara luar tidak sekadar mengimport teknologi daripada sudut peralatan fizikal, tetapi turut membawa nilai-nilai tertentu bersama teknologi tersebut.Beliau mendakwa bahawa teknologi bukan bebas nilai (value free) tapi sarat nilai (value laden).

\section{Pendakwah dan Mawdu 'Dakwah}

Dalam dunia teknologi seperti teknologi desruptif, pendakwah berhadapan dengan lambakan maklumat apabila berlaku penambahan laman web baharu dan kaedah pencapaian maklumat yang begitu senang, mudah dan pantas. Justeru, apabila bercakap tentang teknologi desruptif perkara-perkara seperti kelajuan internet atau speed internet connection, artificial intelegence, big data analysis dan cloud technologies memerlukan suatu penghadaman terperinci dalam menguasai bahasa teknologi terutama ketika berhadapan dengan maklumat yang terlalu banyak yang tidak pasti kebenaran dan kesahihannya.

Menurut Zulkiple (2002) pertambahan ruang dalam dunia maya melalui kecanggihan teknologi menimbulkan persoalan tentang keupayaan untuk melakukan pemilihan maklumat yang benar-benar dikehendaki tetapi tepat dan sahih daripada kebenarannya.Keadaan ini menyebabkan wujud istilah informasi produktif' yang merujuk kepada maklumat yang relevan, terbaru, mencukupi dan boleh diharapkan untuk memenuhi sesuatu tujuan.Dari sinilah mawdu' dakwah terpaksa bersaing dengan mawdu'-mawdu' lain di alam maya bagi menentukan siapakah yang berjaya menambat hati pengguna atau pembaca terutama dalam membentuk public opinion.Malah, lambakan maklumat menyebabkan individu muslim sukar menentukan mana satukah maklumat yang benar-benar bermakna. Percampuran maklumat antara yang mempunyai elemen positif dan negative menyukarkan mereka mencari makna yang sebenar.lambakan maklumat kadang-kadang menyebabkan ada yang berfikiran menjadi petanda berkembangnya ilmu pengetahuan, tetapi menurut alQaradawi (1988) yang tidak berkembang ialah keimanan seseorang. Apatah lagi, seseorang boleh hilang makna kemanusiaannya disebabkan maklumat yang tidak tepat. Teknologi yang sepatutnya memudahkan manusia mencari maklumat, tetapi apabila teknologi menjadi tuan kepada manusia, manusia menjadi hamba kepada teknologi menyebabkan hilang rasa kemanusiaan dalam diri manusia.

Islam mengajarkan agar melakukan tabayun sebagaimana yang terkandung di dalam surah al-Hujurat ayat 6 apabila menerima berita daripada seseorang yang diragui kredebilitinya seperti seorang yang fasik. Ini memerlukan proses penyaringan, penyemakan, pengkajian dan penapisan sesuatu maklumat agar ia benar-benar sahih sebelum disebarkan 
atau dikongsikan kepada orang lain. Walau bagaimanapun, dalam dunia maya, proses penyaringan dan pemerosesan maklumat terutama yang berkaitan dengan Islam pada pandangan Zulkiple (2002) memerlukan kemahiran baru untuk menjadikan umat Islam lebih produktif, bukan sahaja melakukan selection terhadap maklumat, tetapi menyimpannya dengan lebih selamat dan memperolehinya kembali dengan pantas apabila diperlukan.

\section{Pendakwah dan Mad'u}

Dakwah dalam era teknologi desruptif tidak terlepas daripada berhadapan dengan digitalization. Dengan kata lain, pendakwah berada dalam persekitaran digital yang merujuk kepada persekitaran yang dibentuk oleh alat-alat (devises) elektronik seperti komputer, teknologi internet, telefon pintar mudah alih dan pelbagai peranti yang memasuki ruang komunikasi secara nyata dan maya. Persekitaran digital, menurut Zulkiple (2019) boleh memasuki setiap bidang kehidupan dan ia sukar dipisahkan, dari ruang peribadi di rumah seperti peralatan rumah hingga ke ruang publik seperti di dalam institusi pendidikan, perniagaan, kerajaan dan kerohanian.

Justeru, antara cabaran bagi pendakwah dalam persekitaran digital ialah berhadapan dengan kelompok besar sasaran dakwah yang berada di dalam dunia maya atau dipanggil sebagai warga jaringan internet (netizen).Malah menurut Nowshad Amin (2019), warga sesebuah negara rata-ratanya ialah netizen dalam konteks memberikan respon kepada sesuatu persoalan dalam sesebuah negara. Kelompok netizen berkenaan mempunyai karakter yang berlainan daripada segi cara berfikir dan bertindak. Dengan ini budaya netizen memerlukan pendekatan dakwah yang berbeza walaupun menggunakan manhaj rabbani seperti al-hikmah, al-maw izah al-hasanah dan al-mujadalah al-husna.Sebagai contoh Majlis Agama Islam Selangor (2016) ketika membincangkan persoalan generasi muda dalam cabaran berdakwah mengemukakan kelompok generasi yang perlu diambil perhatian terutama para pendakwah yang berdakwah dalam persekitaran digital. Rata-rata pendakwah yang ada merupakan pendakwah daripada generasi Baby Boomer (BB) dan generasi X. Walaupun mereka pernah berhadapan dan menggunakan teknologi tertentu, tetapi cabaran teknologi dalam persekitaran digital ada pada Generasi Y dan Z. Generasi Y misalnya dikenali sebagai generasi alam maya dan generasi facebook, twitter, instagram dan myspace. Generasi Z pula generasi yang lebih savy menggunakan internet, aplikasi maya, lebih bersifat terbuka, tidak boleh hidup tanpa teknologi dan sebagainya. Sudah pasti kesemua generasi 
boleh dilihat perbezaan daripada segi nilai kehidupan, perspektif kehidupan, pola berfikir dan gaya meletakkan priority dalam kehidupan harian. Sebagai contoh aspek priority gaya kehidupan harian Generasi Y memiliki daya kreativiti yang sangat baik apabila melihat sesuatu seni sebagai suatu yang positif dan menggembirakan. Mereka suka banyak bertanya"kenapa" dan "mengapa". Mereka suka mengamalkan "tiruvasi" iaitu tiru dan menginovasikan apa yang ditiru dalam bentuk lain. Daripada sudut cara berkomunikasi pula generasi Y lebih suka berkomunikasi tanpa suara, iaitu berkomunikasi menggunakan teks dan komunikasi alam maya. Mereka mempunyai ramai kawan di alam maya yang mereka tidak pernah menemuinya di alam nyata atau bersua muka. Mereka lebih suka berkomunikasi menggunakan aplikasi mudah seperti WhatsApp, Beetalk, Line, Geogle Talk, Skype, Oovoo, Kakaotalk dan sebagainya berbanding email mahupun surat secara konvensional. Malah mereka mahu berhubung tanpa batasan waktu dan sempadan. Mereka suka berkomunikasi menggunakan ayat komunikasi yang ringkas, padat, terus kepada maksud dan kadang-kadang membina struktur ayat dan perkataan sendiri yang hanya difahami oleh kelompok yang sama. Daripada sudut penghayatan bahasa dan budaya pula generasi $\mathrm{Y}$ suka menggunakan bahasa yang ringkas, padat, singkat dan tidak formal.Kadang-kadang mereka gagal berbicara dengan bahasa peradaban dan sopan dalam penilaian generasi $\mathrm{X}$ dan $\mathrm{BB}$.

Malah dalam kajian Faizahtun Husna (2018), pendakwah perlu berhadapan dengan warga netizen yang mempunyai pelbagai personality seperti personality introvert dan ekstrovert. Mereka dinilai daripada sudut emosi, gaya berfikir dan kehidupan sosial. Ciri-ciri introvert secara umum, mereka adalah yang mempunyai personality pasif, emosional, pendiam dan kurang sosialisasi. Lebih fokus kepada pemikiran berbanding perasaan.

○ Emosi

- Lebih berusaha memahami diri sendiri berbanding orang lain

- Keras hati, sombong

- Tidak memerlukan rangsangan dunia luar untuk bertindak

- Sesuatu perasaan yang dialami berpanjangan seperti mengekalkan persahabatan dalam tempoh yang lama; permusuhan/kemarahan yang lama \& berpanjangan

- Hiba

- Kemurungan yang melampau

- Boleh mendorong melakukan sesuatu yang menyakiti diri sendiri dan membunuh diri 
○ Gaya berfikir

- Sukar bergandingan dan berkongsi idea dengan orang lain

- Idea bersifat abstrak/penuh dengan teori

- Memberi tumpuan lebih dalam pelbagai aspek

- Suka melakukan dan menyiapkan tugasan secara individu tanpa mengharapkan bantuan orang lain

- Fokus kepada aspek pemikiran

- Setiap keputusan sukar dilaksanakan

- Tidak mempunyai cita-cita yang tinggi

- Kurang mengambil inisiatif

- Suka berkhayal

- Mudah mengelamun dalam dunia sendiri

- Tidak menekankan aspek praktikal

- Sukar difahami oleh orang lain

- Mempunyai kesukaran dalam menghadapi kehidupan seharian dan perancangan masa hadapan.

○ Kehidupan sosial

- Lebih serius

- Pemalu

- Kurang selesa dengan perubahan

- Lebih cenderung kepada sistem yang teratur dan sistematik

- Lebih suka bersendirian

- Tidak memerlukan rangsangan luar untuk bertindak

- Apabila mempunyai masalah lebih suka menyendiri dan memendam perasaan

- Seolah-olah tabah di alam nyata kerana tidak mempamerkan masalah kepada orang lain

- Suka berwaspada/berhati-hati/berjaga-jaga dalam pelbagai aspek

- Tidak suka menjadi tumpuan orang ramai

- Suka mengikut peraturan yang ditetapkan

- Mempunyai disiplin diri yang tinggi

- Tidak begitu agresif dalam perbualan

- Sensitif dengan perpisahan 
Manakala mereka yang dikategorikan sebagai ekstrovert mempunyai ciri-ciri berikut:

○ Emosi:

- Bebas melahirkan perasaan dan emosi

- Rapat dengan peraturan masyarakat

- Lebih emosional

- Kurang peka dan sensitif dengan pendapat dan harapan orang lain

- Mudah meluahkan perasaan yang dialaminya kepada orang yang berada di sekelilingnya

- Sering bertindak balas pada orang lain secara emosional yang menimbulkan rasa tidak selesa pada orang lain

- Suka bergaduh apabila pendapatnya tidak dapat diterima orang lain

○ Gaya berfikir

- Gemar dengan dunia luar

- Suka melibatkan diri dengan orang ramai

- Lebih tertarik dengan idea-idea baharu

- Berusaha dengan lebih kreatif

- Bersikap objektif dalam aspek kehidupan

- Dapat menerima sesuatu peraturan yang dikira rigid atau tidak dapat diubah suai/dipersoalkan lagi

- Gemar mengaplikasikan pemikiran lojik ketika menghuraikan dan memahami alam semula jadi

- Keputusan dilakukan berdasarkan gerak hati berbanding dengan situasi atau peristiwa.

○ Kehidupan sosial

- Agresif dan aktif dalam tindakan

- Lebih gemar bersosial dan melibatkan diri dengan aktiviti sosial

- Suka bergaul dengan orang lain samada dikenali atau tidak

- Seperti orang yang 'lurus' tetapi disukai ramai

- Gemar menjadi tumpuan orang ramai

- Optimis dan menyokong perubahan

- Berusaha mencari pengalaman baharu yang dapat memberikan kepuasan

- Berusaha mengadaptasi diri dengan dunia nyata 
- Senang menyesuaikan diri dengan pelbagai golongan manusia dan situasi tanpa segan silu/malu

- Bebas daripada kebimbangan melampau.

- Tidak suka berseorangan

- Kurang senang dengan perkara-perkara yang menyedihkan.

Sementara itu, dalam kajian Nor Faizah (2018) mendapati antara ciri-ciri netizen ialah sikap suka menunjuk-nunjuk, suka expose diri tanpa mempunyai matlamat yang jelas, inginkan/sukakan sanjungan dan perhatian rakan-rakan netizen di media sosial seperti memuat naik gambar jam tangan sendiri dengan meletakkan kapsyen "alamak! Dah lambat masuk kuliah", berlumba-lumba memaparkan kisah peribadi sendiri tanpa tujuan yang jelas, inginkan pujian dan sanjungan, rasa kagum dengan diri sendiri, inginkan perhatian yang lebih daripada orang lain dan merasakan diri lebih istimewa daripada orang lain.

Tidak keterlaluan, warga netizen, dalam pemerhatian Nowshad Amin (2019), yang tinggal di dalam dunia virtual telah berubah corak pemikiran akibat teknologi yang mempunyai "more informed" tetapi "not knowledgeable and action-less due to lack of profer education or training with emotional maturity". Mereka menikmati teknologi desruptif yang begitu banyak tetapi kelihatan mereka menghidap risiko seperti "ill-health, irregular lifestyle, poor ethical values and similar".

\section{E. Penutup}

Dakwah dalam ekosistem dan persekitaran teknologi desruptif memerlukan penguasaan ilmu pengetahuan yang pelbagai yang bermula dengan ilmu pengetahuan berteraskan Islam, ilmu sains dan teknologi serta ilmu kemanusiaan. Aspek manhaj rabbani sebagai perkara penting dalam proses pendakwahan. Walaupun dakwah bersifat dinamik yang meraikan inovasi dan penciptaan baharu, tetapi aspek manhaj rabbani tidak boleh dikesampingkan.Teknologi yang memudahkan pergerakan seseorang boleh dijadikan titik penting bagi merealisasikan maksud kebaktian kepada sesama manusia yang menjadi kayu pengukur kepada kebaikan seseorang. Malah teknologi yang ditandai dengan peralatan dan proses menggunakannya tidak lebih sekadar peralatan yang tidak boleh menjadi matlamat kehidupan seseorang. Apatah lagi manusia dan unsur kemanusiaan sejati tidak boleh ditukar ganti dengan teknologi supaya proses tranhumanisme dan debuman tidak berlaku dalam kehidupan manusia. 


\section{DAFTAR KEPUSTAKAAN}

Al-Bayanuni, Muhammad Abu al-Fath (1995) Al-Madkhal Ila 'Ilm al-Da 'wah. Beirut: Mu'assasah al-Risalah.

Al-Qaradawi (1988),Yusuf. Al-Islam Hadarah al-Ghad (Islam Teras Tamadun Masa Depan).Terj. Asril Ibrahim. Kuala Lumpur: Institut Terjemahan Ngara Malaysia Berhad.

Bani Amir, Muhamad Amin Hassan Muhammad (1999) Asalib al-Da wah wa al-Irshad. Yarmuk: Jami`at al-Yarmuk.

Drucker, P.F (1995) Realiti Baru. Terj. Nazlifa Ali. Kuala Lumpur: Dewan Bahasa dan Pustaka.

Faizahtun Husna Adnan (2018) Perbandingan Personaliti Introvert dan Ekstrovert Dala Penggunaan Media Baharu antara Alam Nyata dan Alam Maya.Latihan Ilmiah Pengajian Islam Universiti Kebangsaan Malaysia.

Hamid Mowlana (1993) The New Global Order and Cultural Ecology. Media, Culture and Society. Jilid 1, No. 1, January 1993: 9-27.

Majlis Agama Islam Selangor (2016).Generasi Muda: Cabaran dan Dakwah. Shah Alam: Majlis Agama Islam Selangor.

Nor Faizah Ismail (2018) Pengaruh Pengguna WhatsApp Terhadap Kesedaran Islam dan Tingkablaku Beragama Islam Dalam Kalangan Mahasiswa.Tesis Sarjana Pengajian Islam Universiti Kebangsaan Malaysia.

Nowshad Amin (2019) Inspiring the Youth towards Green Dismuptive Technologies and Lifestyle. Kertas kerja IKIMM National Colloqiumm Series on Islamic Understanding, "Islam and Disruptive Technologies” pada 22 Oktober 2019 di Institut Kefahaman Islam Malaysia (IKIM).

Ziauddin Sardar (1993) Paper, Printing and Campact Disc: the Making and Unmaking of Islamic Culture. Media, Culture amd Society. Vol 15: 43-59.

Zulkefli Aini \& S.Salahudin Suyurno (2016) Pengantar Komunikasi Dakwah. Bangi: Jabatan Pengajian Dakwah dan Kepimpinan UKM.

Zulkiple Abd Ghani (2010) Dakwah dalam Era Digital di Malaysia. Nilai: Penerbit Universiti Sains Islam Malaysia.

Zulkiple Abd Ghani (2019) Ekosistem Dakwah dalam Era Digital. Siri Syarahan Perdana. Nilai: Penerbit Universiti Sains Islam Malaysia.

Zulkiple Abd.Ghani (2002) Cabaran Dakwah Islam di Era Siber.Jumal Usuluddin. Bil 5: 133-142. 